\title{
ALGUMA POESIA E A TÉCNICA
}

\section{'SOME POETRY' AND THE TECHNIC}

\author{
João Batista SANTIAGO SOBRINHO ${ }^{1}$ \\ a rua acabou, quede as árvores? a cidade sou eu \\ a cidade sou eu \\ sou eu a cidade \\ meu amor. \\ Carlos Drummond de Andrade, 2012, p.102
}

\begin{abstract}
Resumo: Sempre encontramos na poesia de Carlos Drummond de Andrade uma preocupação crítica com os rumos civilizacionais. Este texto pretende, pois, expor, no primeiro livro do poeta mineiro, Alguma poesia, publicado em 1930, uma gênese dessa preocupação. Para colocarmos em evidência essa temática, nos utilizaremos da crítica literária e filosófica, bem como de alguns poemas drummondianos, nos quais o poeta problematiza, ao longo de sua poesia, uma tensão entre a técnica e a vida.
\end{abstract}

Palavras-chave: poesia, técnica, filosofia, crítica literária.

\begin{abstract}
We always found in the poetic of Carlos Drummond de Andrade - a brazilian poet from Minas Gerais - a criticism upon the process of civilization. In this paper, we focus on the first book of the poet, intitled "Some Poetry", first published in 1930, so to say, the foundation of his speculations. To approach this subject we dialogue with the literary and philosophical criticism and also with his poems. In a way,
\end{abstract}

\footnotetext{
${ }^{1}$ Professor, Departamento de Linguagens e tecnologias, Centro federal de Educação Tecnológica de Minas Gerais, CEFET-MG, 30421169, Belo Horizonte, Minas Gerais, Brasile joaoliter@hotmail.com
} 
Drummond's poetic problemizes the tensions between technic and life.

Keywords: poetry, technic, philosophy and literary criticism.

A poesia drummondiana, desde o início, problematizou a relação do homem com o meio. Por essa razão, Manuel Bandeira dirá que Carlos Drummond é o poeta da "emoção social", seara que, segundo Manuel Bandeira, ele só atingiu em meia dúzia de poemas (BANDEIRA, 1984, p.102). E é justamente em meio a essa emoção que perscrutamos, na poesia de Drummond, a presença da técnica, da qual daremos notícia conceitualmente um pouco mais à frente. A expressão de Bandeira possui a delicadeza de não enquadrar o poeta mineiro para além da verdade poética, essa grande estrela no firmamento da linguagem de Drummond. Nesse sentido, este texto irá explorar, no livro Alguma poesia, o fio nascente e tentacular dessa preocupação com os rumos civilizacionais, que se estenderá, por fim, a toda escritura de Carlos Drummond de Andrade. Para tanto, nos utilizaremos da filosofia, mormente aquela envolvida com a crítica à técnica, bem como da crítica literária que contribua para a visualidade temática que ensejamos. Este texto é fruto das pesquisas que temos realizado no grupo de pesquisa "Literatecnica: estudos sobre literatura, outras artes e técnica”, do Centro Federal de Educação Tecnológica de Minas Gerais (Cefet-MG).

O livro Alguma poesia pertence à geração de 1930, no entanto, muitos dos seus poemas foram escritos ao longo dos anos 20 do século passado, portanto, na fase "heroica do modernismo" e sob forte influência das vanguardas europeias e todo o aparato estéticosocial que àquele momento hiperbólico se firmava. Drummond, a exemplo de outros modernistas, não se deixa contaminar pelo futurismo de Filippo Tommazo Marinetti, expressão estética das vanguardas mais entusiasta da técnica.

Marinetti, ideólogo e poeta do futurismo, de acordo com Nikos 
Stangos, "queria que as artes demolissem o passado e celebrassem as delícias da velocidade e da energia mecânica" (STANGOS, 2000, p.85); com esse pathos técnico, Marinetti logo se encaminharia para a expressão máxima da técnica em sua época, o fascismo e o nazismo e, consequentemente a guerra.

Ao tratar sobre a estetização da vida política no texto "Estética da guerra”, em 1935/1936, Walter Benjamin, fará duras críticas às ideias de Marinetti:

A política se deixou impregnar, com d'Annunzio, pela decadência, com Marinetti, pelo futurismo, e com Hitler, pela tradição de Sachwabing [bairro boêmio de Viena]. Todos os esforços para estetizar a política convergem para um ponto. Esse ponto é a guerra. A guerra e somente a guerra permite dar um objetivo aos grandes movimentos de massa, preservando as relações de produção existentes. Eis como o fenômeno pode ser formulado do ponto de vista político. Do pondo de vista técnico, sua formulação é a seguinte: somente a guerra permite mobilizar em sua totalidade os meios técnicos do presente, preservando as atuais relações de produção. (BENJAMIN, 1985, p.195; grifos do autor).

Benjamin enfaticamente combate a expressão de Maninetti: "a guerra é bela", que se repete em um manifesto do futurista sobre a guerra colonial da Etiópia.

Embora saibamos que Alguma poesia não traduz de maneira intensa a "emoção social", é no âmbito dessa mirada drummondiana que encaminharemos nossa investigação de uma poesia que nasce justamente no início do "século da guerra", ou "sob o paradigma da guerra”, na visão de Alain Badiou, que, no livro O século (2007, p.60), interpreta o século XX como aquele mais violento da história da humanidade. Ainda de acordo com o filósofo, depois de uma largada luminosa de "criatividade polimorfa", semelhante à Renascença florentina ou ao "Século de Péricles", o século XX se estabelece como longa tragédia, marcada sobretudo por uma efervescência criativa, com vistas a criar um "novo homem", e "criar um novo homem 
equivale sempre a exigir que o homem seja destruído" (BADIOU, 2007, p.21). Para Badiou,

0 projeto do homem novo é nesse sentido projeto de ruptura e de fundação que sustenta, na ordem da história e do Estado, a mesma tonalidade subjetiva que as rupturas científicas, artísticas, sexuais do início do século. É, portanto, possível afirmar que o século foi fiel ao seu prólogo. Ferozmente fiel. (BADIOU, 2007, p.21).

Badiou quer dizer que o século da guerra, em vista do que anunciava em seu prólogo, o intento de criar um novo homem, resultou num processo de violência sem precedentes cujo ápice concentra-se, pode-se dizer, no projeto de estetização proposto e colocado em prática pelo Nacional Socialismo alemão.

A poética drummondiana assume postura corrosiva quanto ao "novo homem", encontrando forte apelo, por exemplo, no poema "Especulações em torno da palavra homem" (DRUMMOND, 2002, p.428), do livro A vida passada a limpo, de 1958, poema que se encerra com a pergunta "mais que coisa é o homem?", retomada no poema "Novo homem", do livro Versiprosa, de 1967:

"Nove meses eu?

Nem nove minutos."

Quem já concebeu

melhores produtos. (ANDRADE, 2002, p.638).

A "coisificação" do "novo homem" fica evidente quando o poeta o chama de "produto", rimando com o tempo de fabricação ajustado ao timing de produtividade mercantil. 0 poema se constrói tensionando o velho homem, "defeituoso", o homem "antigório", com o homem novo, e termina com os versos:

eis que o homem feito

em laboratório

sem qualquer defeito

como no antigório, 
acabou com o homem.

Bem feito. (ANDRADE, 2002, p.640).

Para acabar com o homem velho, a técnica, o século $\mathrm{XX}$, atendendo ao seu "prólogo", lançou-se com avidez no projeto de criação do homem novo. 0 poema drummondiano, como não podia deixar de ser, encerra sua jornada de maneira irônica, com a expressão dúbia, aberta: "Bem feito". Bem, no sentido, de "bens" e de "coisa", do poema "Especulações em torno da palavra homem", mercadoria bem acabada, bem feita; e "Bem feito!" no sentido do sarcasmo machadiano de "ao vencedor, as batatas", ao fim, tem-se o que se fez por merecer.

Manuel Bandeira, em Itinerário de Pasárgada, comentando o que ele chama de "emoção social", afirma:

intenso é meu desejo de participação, mas sei, de ciência certa, que sou um poeta menor. Em tais altas paragens só respira à vontade entre nós, atualmente, o poeta que escreveu o Sentimento do mundo e Rosa do povo. (BANDEIRA, 1984, p.102).

De muitas maneiras, nossa leitura sobre Alguma poesia advém de uma mirada sobre os dois livros citados nesse recorte bandeiriano e, para dar sequência ao nosso olhar sobre a poesia de Drummond, também a contribuição de Umberto Galimberti para a compreensão do que seja a "técnica" é decisiva. Seu conceito de técnica chama a atenção para a racionalidade, a funcionalidade e a eficiência que, no imaginário social, se assentam como instâncias imprescindíveis e inquestionáveis:

com o termo técnica entendemos tanto o universo do meios (tecnologias), que em seu conjunto compõem o aparato técnico, quanto a racionalidade que preside seu emprego, em termos de funcionalidade e eficiência. (GALIMBERTI, 2006, p.9). 
Ainda, corroborando o conceito de técnica de Galimberti, utilizamos o conceito de "dispositivo" de Giorgio Agamben, que o constrói a partir, por exemplo, dos estudos de Foucault, Heidegger e Marcuse, e o expõe às forças hegemônicas que reforçam a visão tecnocrata do mundo, da qual participam o capitalismo e as instâncias que o sustentam, dando origem àquilo que Agamben chama de "dispositivo" e Heidegger "armação", ou seja, a "máquina que produz subjetivações" (AGAMBEN, 2012, p.46). Assim, o conceito de "dispositivo", para o filósofo italiano, abarca

qualquer coisa que tenha de algum modo a capacidade de capturar, orientar, determinar, interceptar, modelar, controlar e assegurar os gestos, as condutas, as opiniões e os discursos dos seres viventes. (AGAMBEN, 2012, p.40).

Os poemas de Alguma poesia deixam entrever vestígios de uma crítica problemática à técnica, que se acentuará em poemas como "Sentimento do mundo" (DRUMMOND, 2012, p.205), no qual o poeta retrata uma espécie de "campo de guerra" - expressão mais acabada da técnica - em que a vida se transformara; e "A noite dissolve os homens" (DRUMMOND, 2012, p.246), em que o mesmo cenário se repete. Mas, sobretudo, é no livro Rosa do povo, no qual "melancolias, mercadorias" espreitam o poeta, no poema "A flor e a náusea" (DRUMMOND, 2012, p.310), que ocorrerá um dos momentos mais fortes de "emoção social". É esse mesmo poema que traz o nascimento de uma flor que, para além de seu aspecto metalinguístico, é metonímia da natureza, presença intensa no imaginário drummondiano, que, ao longo de toda a sua produção poética, se contrapõe quase sempre ao modelo civilizacional:

Uma flor nasceu na rua!

Passem longe, bondes, ônibus, rio de aço do tráfego.

Uma flor ainda desbotada

ilude a polícia, rompe o asfalto.

Façam completo silêncio, paralisem os negócios, garanto que uma flor nasceu. 
Sua cor não se percebe.

Suas pétalas não se abrem.

Seu nome não está nos livros.

É feia. Mas é realmente uma flor.

(ANDRADE, 2012, p.311).

Naturalmente que a flor, metonimicamente, pode simbolizar a esperança frágil em oposição à "razão instrumental", cujos dispositivos "bondes", “ônibus", "tráfego", "polícia”, “asfalto" exprimem.

Essa condição ulterior da escritura mais incisiva do poeta em relação aos rumos civilizacionais nos obriga a reler Alguma poesia com olhos mais argutos em relação ao tema que propusemos. Em que pese a recolha do poeta no livro Claro enigma, marcado por uma espécie de cansaço agudo ou recusa trágica mediante a ineficácia da luta do homem por um mundo mais justo, a "emoção social" nunca abandonará o poeta. Quase sempre se pode notar esse aspecto na poesia de Drummond, sobretudo na dimensão de um apreço à natureza, cuja menção ocorrerá necessariamente por conta do seu massacre perante o processo civilizatório, ou seja, as forças da técnica que, de acordo com Galimberti, crescem concomitantemente à destruição da natureza. Ressaltamos que não há em Drummond um discurso do inocentação ou da culpabilização, nada escapa à escritura corrosiva do poeta, que compreende que a vida é uma resultante problemática de forças. É o que ele faz ver em poemas como, por exemplo, "Tarde de maio", do livro Claro enigma, quando trata da guerra, misturando-a ao labor de uma subjetividade furiosa que espelha a devastação do mundo:

quando, ao rubor dos incêndios que consumiam a terra, outra chama, não perceptível, e tão mais devastadora, surdamente lavrava sob meus traços cômicos (ANDRADE, 2012, p.596-597).

Vemos, nessa cena de guerra, uma espécie de suma do que seja a técnica, ou seja, ela é uma forma de pensamento - "outra chama", 
uma força que "surdamente lavrava sob meus traças cômicos" - e não, conforme se imagina em geral, uma dimensão externa ao homem. Em verdade, a técnica é mais "uma visão de mundo", é uma maneira de desvelar o mundo, para usar um termo caro a Heidegger, que afirma que a "a essência da técnica não é, de forma alguma, nada de técnico" (HEIDEGGER, 2008, p.11).

Alguma poesia foi publicado em 1930, edição em 500 exemplares, paga pelo autor. 0 mundo vive, então, um momento extremamente crítico, a crise de 1929. Uma crise, sem precedentes, do capital. 0 poema "Outubro 1930" (DRUMMOND, 2012, p.139) retrata, com ares autobiográficos, já que Drummond participou ativamente da revolução de 1930, que contribuiu para levar Getúlio Vargas ao pode:

de 5 em 5 minutos um ciclista trazia ao Estado-Maior um feixe de telegramas contendo, comprimida, a trepidação dos setores. 0 radiotelegrafista ora triste ora alegre empunhava um papel que era a vitória ou a derrota. Nós descansávamos, jogados sobre poltronas, e abríamos para as notícias os olhos que não viam, olhos que perguntavam. Às 3 da madrugada, pontualmente, recomeçava o tiroteio. (DRUMMOND, 2012, p.139).

O poema em prosa, acima, compõe a segunda estrofe de "Outubro 1930", no entanto, se pode afirmar que é um retrato do século XX, tomando-o já como século da guerra. Sobre esse assunto, Drummond irá falar de maneira mais ou menos íntima numa prosa com Ary de Andrade, que será registrada no texto produzido a partir de uma conversa entre esses dois gauches: "0 mundo de apósguerra”, do primeiro volume da Coleção Fortuna Crítica, dirigira por Afrânio Coutinho. Ary de Andrade pergunta a Drummond, "Como lhe parece o mundo de após-guerra?", tomando como referência a Segunda Guerra Mundial. Entre o que disse o poeta sobre o pósguerra, recolhemos a seguinte passagem:

Para que se pudesse dizer que este conflito não foi em vão 
e veio beneficiar a humanidade, seria preciso que nesse amanhã, de que estamos ainda num sombrio princípio de aurora, trouxesse melhores condições de vida, habitação, cultura, subsistência para todos os homens, sem distinções nem discriminações, quaisquer que elas fossem. Que às bibliotecas fosse permitido o acesso aos que tem os pés descalços (ou antes, que não houvesse mais pés descalços no mundo...) mas, esquecidos das vísceras, têm fome e sede de saber. Que os museus não fossem só para privilegiados capazes de apreciá-los pelo seu nível de cultura. Que os homens que nada possuem pudessem frequentar esses lugares como podem agora viajar nos bondes de segunda classe. Porque, nas atuais condições econômicas vigentes na maior parte da superfície da terra, e apesar do que se diga em contrário, a cultura continua a ser um privilégio de classe e de casta. (ANDRADE, 1977, p.32).

No trecho acima, a "emoção social" salta aos olhos. Não só por sua lucidez de análise e seu diálogo com a própria poética drummondiana, mas por sua atualidade. Drummond se utiliza da pergunta sobre o pós-guerra para trazer sua reflexão para o âmbito da guerra cotidiana, que, afinal, constitui o próprio viver mediante as forças político-sociais que nitidamente privilegiam as classes mais abastadas. E, para o poeta, a guerra - expressão radical da técnica - resultaria em nada caso não pudesse ela mudar as condições de desigualdade social.

Isto posto, dentre os poemas do livro Alguma poesia, cuidaremos de problematizar apenas alguns que fizerem direta ou indiretamente alguma alusão à técnica.

Em princípio, a presença da técnica ocorre apenas como ilustração do cotidiano, donde o poeta, acolhendo um preceito modernista, extrai sua poesia. Isso não quer dizer uma ausência de problematização do "eu lírico" em relação à técnica. Se "bonde", no "Poema das sete faces", é espaço para o voyeurismo drummondiano, posteriormente, a presença desse dispositivo será acrescida de suas razões, digamos, técnicas. Nesse poema, é notória a dimensão 
do corpo que, na perspectiva que adotamos, se torna importante, em razão de uma mirada pós-orgânica que torna o corpo obsoleto para o "ideário fáustico da tecnociência contemporânea", conforme, Paula Sibilia (2002, p.63), por exemplo. Esse ideário fáustico consistiria num pacto, numa aceitação incondicional às promessas da técnica. Certamente, não é isso que vemos em Drummond. Embora se possa perceber que, ao fim, o corpo é a única dimensão da existência em que o eu lírico drummondiano se veja dividido. Essa divisão é exposta nos versos do poema "Missão do corpo", do livro póstumo, Farwell, do qual recortamos as seguintes passagens:

\author{
Em ti me sinto dividido, campo de batalha \\ sem vitória para nenhum lado \\ e sofro e sou feliz \\ na medida do que o acaso me oferece \\ Será mesmo acaso, \\ será lei divina ou dragonária \\ que me parte e reparte em pedacinhos? \\ Meu corpo, minha dor, \\ meu prazer e transcendência, \\ és afinal meu ser inteiro e único.
} (ANDRADE, 2002, p.1418-1419).

Essa declaração de que o corpo é o "ser inteiro e único" do poeta nos parece exemplar no sentido de que essa é a instância da qual tudo o mais se deflagra, o campo de batalha primeiro, donde resulta, por assim dizer, o mundo no qual ocorrem as "outras" batalhas, que são, por sua vez, resultado das projeções do corpo - a dimensão da "guerra" no significante "batalha", problematizada também no poema "Tarde de maio", conforme vimos, anteriormente, neste texto.

Como desdobramento desse sentimento tão drummondiano do estar no mundo - no mundo que se desvelava naquele século $\mathrm{XX}$-, encenam-se as progressivas mudanças cuja ambiguidade, no sentido de um encantamento/desencantamento, explora o eu lírico no poema "A rua diferente": 
Na minha rua estão cortando as árvores

botando trilhos

construindo casas.

Minha rua acordou mudada.

Os vizinhos não se conformam.

Eles não sabem que a vida

tem dessas exigências brutas.

Só minha filha goza o espetáculo

e se diverte com os andaimes,

a luz da solda autógena

e o cimento escorrendo nas formas.

(ANDRADE, 2012, p.78).

Há no poema "A rua diferente" a primeira constatação mais contundente de que as mudanças festejadas no projeto modernista, cujo exemplo maior, no Brasil, à época, era a cidade de São Paulo, não goza de tanto prestígio assim aos olhos do povo e do eu lírico apesar da "filha" deste gozar o "espetáculo". E, apesar da aparente serenidade com que mostra saber que a vida tem suas "exigências brutas", o poema deixa entrever um grau de insatisfação que se pode inferir como sendo também do eu lírico. 0 mesmo clima, agora sem nenhuma intervenção do eu lírico, ocorre no poema "Construção":

Um grito pula no ar como um foguete.

Vem da paisagem de barro úmido, caliça e andaimes hirtos.

O sol cai sobre as coisas em placas fervendo.

0 sorveteiro corta a rua.

E o vento brinca nos bigodes do construtor. (ANDRADE, 2012, p.62).

Esse poema, que antecede na enunciação e no enunciado, o poema "Uma rua diferente" - este editado em 1928 e aquele em 1925 -, tem uma marcação mecânica, que os pontos finais, a cada verso, enfatiza. De resto, o poeta apenas observa e constata, como um fotógrafo, um flaneur, os acontecimentos intermináveis do devir civilizacional, como a imagem final do poema, "e o vento 
brinca nos bigodes do construtor", metalinguisticamente faz ver, pois o construtor, pode-se também inferir é o eu lírico que constrói as imagens, que constrói o poema.

Em outro caso, o poema "Cidadezinha qualquer" se opõe, naturalmente, a uma das dimensões mais caras à técnica, a velocidade, esta que, para Paul Virilio, no livro $A$ velocidade de libertação (2000) representa uma espécie de libertação da matéria:

Casa entre bananeiras
mulheres entre laranjeiras
pomar amor cantar
Um homem vai devagar
Um cachorro vai devagar
Um burro vai devagar
Devagar... as janelas olham.
Eta vida besta, meu Deus.
(DRUMMOND, 2012, p.109).

A vagareza se notabiliza por oposição implícita à velocidade dos grandes centros urbanos. Mas, mesmo aí, a técnica, com seu projeto totalitário, já atravessa o sertão, e, se antes o fazia de "carroça", urge fazê-lo de trem, ou seja, à luz de uma modernização que acerte os ponteiros brasileiros com o resto do mundo, não apenas no âmbito estético, mas também tecnológico. Não estamos afirmando que o poema drummondiano aventa essa proposta, mas ela é frequente ao momento em que Drummond escrevia Alguma poesia e ressoa em sua produção na condição revelada mais tarde pelo eu lírico, sobretudo quando este afirma, epigramaticamente, no poema explicação: "no elevador penso na roça,/ na roça penso no elevador". Está aí ou, segundo John Gledson, no livro Poesia e poética de Carlos Drummond de Andrade, seu "provincianismo e seu modernismo" (GLEDSON, 1981, p.59): o provincianismo estaria para "cidadezinha qualquer", ao passo que o cosmopolitismo, explícito, por exemplo, pela presença dos gadgets que traduzissem uma atualização do país com o resto do mundo, estaria para o "modernismo". Mas, ainda de acordo com Gledson, em Drummond, o provincianismo é desconfiado e crítico 
da metrópole (Paris), que Belo Horizonte copia, com seus jardins e arquiteturas, e, nesse sentido, o poeta capta o sentimento oscilante que normalmente nos toma mediante a técnica:

Ao irmos da "roça" para o "elevador", descobrimos que a própria escolha da imagem resume muita coisa. É, sobretudo, o aspecto moderno e mecânico da cidade que interessa ao poeta: quaisquer que fossem as possíveis razões sociológicas deste interesse, não podemos duvidar de sua importância. 0 automóvel é assunto de dois poemas irônicos, "Cota zero" (O. C. p.71) e "Sinal de apito" (0. C. p.68); e, "Nota social", o poeta melancólico está cercado de automóveis, máquinas, fotografias e elevadores; "Poema do jornal" (O. C. p.63) comenta as novas máquinas de construção. Num sentido mais metafórico, também, há uma forte tendência a ver a sociedade urbana no seu aspecto mecânico. Poemas como "Sociedade" (O. C. p.73), "Família" (0. C. p.69), "Moça e soldado" (0. C. p.70), e "0 que fizeram do natal" (0. C. p.61) mostram seres humanos que obedecem as regras sociais como autômatos. (GLEDSON, 1981, p.68).

Nesse sentido, concordamos com a postura de Gledson, ou seja, Drummond, entre o "elevador" e a "roça", se mantém ironicamente gauche, sem afirmar decididamente ante essa ou aquela dimensão da vida, muito embora não deixe de traduzir uma crítica dura quanto aos rumos civilizacionais, que o "elevador" alegoriza, como esperamos explicitar neste texto.

Essa "demora" da "vida besta" da pequena cidade desaparece, agora por completo, em meio de cabos de fibra ótica ou wireless, "atualizando" toda a gente com a velocidade, digamos, em tempo real. A sensação do tempo veloz é experimentada por praticamente todos. Sobre isso, afirma Paul Virilio: "O tempo mundial é o mundo do tempo único e acabado, que ameaça ter consequências dramáticas sobre o nosso sentimento de realidade" (VIRILIO, 2000, p.194). Esse mesmo filósofo nos lembra a origem da realidade virtual que proporciona experiências em tempo real:

É preciso ver que a guerra é que trouxe a realidade 
virtual: é o desenvolvimento dos simuladores de voo para a US Air Force (na intensão de economizar a gasolina dos bombardeios, bem como vidas humanas) que esteve na base das pesquisas sobre os ciberespaços que são, doravante, objetos lúdicos. Pouco a pouco, desenvolveram tecnologias de simulação de voo dentro do quadro de antecipações da guerra nuclear: fizeram jogos de guerra, war games, que eram jogos não de garotos, mas de estados-maiores, e essa realidade virtual substituiu aos poucos a realidade das manobras terrenas. (VIRILIO, 2000, p.195).

A razão que está por trás da lógica da guerra é instrumental, não visa à outra coisa senão reduzir os custos e aumentar os lucros. 0 termo ironicamente utilizado por Virilio, "economizar", não deixa dúvidas quanto ao caráter racional-instrumental que gerou a descoberta do virtual. Tudo isso, monitorado pela ideia de eficácia, reduz a própria vida aos dispositivos.

O poema, "Cidadezinha qualquer", também nesse sentido, para além da blague, do humor, do poema-piada, se ressignifica para ser uma espécie de crônica de um outro tempo, cuja lentidão e graça, por si mesmas, se opõem à vontade de velocidade da técnica.

No poema intitulado "Europa, França e Bahia”, o eu lírico vê a Europa conforme em geral nos viam, ao sonhar que os europeus é que são "exóticos":

Meus olhos brasileiros sonhando exotismo.

Paris. A torre Eiffel alastrada de antenas como um caranguejo.

0 cais bolorento de livros judeus

e a água suja do Sena escorrendo sabedoria.

(ANDRADE, 2012, p.64).

São os versos iniciais do poema, e são extremamente corrosivos ao desancar o dispositivo iluminista, a torre Eiffel, comparando-a a um caranguejo, que, no imaginário popular, anda para trás. E logo se seguem imagens decadentes relativas ao ocidente judaico, 
expressas num porto "bolorento", “cais" de "livros judeus”, e fecha a estrofe com a sabedoria "suja" que escorre do rio Sena. Tratase de um poema completamente desencantado com os rumos civilizacionais do Ocidente. Em seguida, o eu lírico afirma:

O pulo na Mancha num segundo.

Meus olhos espiam olhos ingleses vigilantes nas docas.

Tarifas bancos fábricas trustes craques.

Milhões de dorsos agachados em colônias longínquas formam um tapete

[para Sua Graciosa Majestade Britânica pisar. E a lua de Londres como um remorso.

(ANDRADE, 2012, p.64).

A presença da Bahia, metonímia de Brasil, nos faz pensar num outro poeta cuja "ira", talvez inda mais corrosiva, recai sobre essa relação de subserviência da colônia para com a Europa. Estamos nos referindo a Gregório de Matos e ao poema que ficou conhecido nesses "tristes trópicos" como "Triste Bahia". Sobre ele, os estudos de Alfredo Bosi, na Dialética da colonização (1992), no capítulo "Do antigo estado à máquina mercante", e de José Miguel Wisnik, no livro Poemas escolhidos de Gregório de Matos (2010), para ficar apenas nesses dois, traduzem com agudeza o clima crítico que o poeta barroco conclama, e que não é outro senão este mesmo que Drummond reencena em relação à "máquina mercante" dos anos de 1930. Nesse encontro entre os dois poetas, o "sagaz Brichote", nome dado aos estrangeiros (HOUAISS, 2001, p.512) por Gregório de Matos, equivale aos "olhos vigilantes dos ingleses nas docas" de que fala Drummond. Em seguida, o eu lírico faz uma suma do que tem sido historicamente a relação da Bahia/Brasil com os dispositivos civilizacionais, e lá em Gregório, como aqui em Drummond, a atualidade dos versos saltam aos olhos.

Além disso, em que pesem outras possíveis representações da lua na obra drummondiana, para o que remetemos, por exemplo, ao artigo de Vivaldo Andrade dos Santos, “0 corpo que não morreu 
especialmente para nos comover" (REVISTA USP, 2006, p. 181192), que traz uma análise do corpo no livro Alguma poesia. No sentido que perscrutamos nos versos acima, podemos inferir que se trata de uma ironia, a personificação da lua, para dizer de uma impossibilidade de remorso por parte de dispositivos e pessoas (como dispositivos) imperantes sob a lua: tarifas, bancos, fábricas, trustes, craques, e, especialmente, "Sua Graciosa Majestade Britânica", os quais capitaneiam o processo civilizatório. "Europa, França, Bahia", ainda alude, de maneira explícita, a dispositivos de guerra, ao se referir, por exemplo, aos "submarinos" (DRUMMOND, 2012, p.64) e ao próprio Mussolini (DRUMMOND, 2012, p.65), nesse poema que, entre outras perspectivas, aborda a relação de exploração mercantilista existente entre a metrópole e a colônia, entre, vale dizer, a "Europa" e a "Bahia".

Assim, este texto consistiu em apontamentos para um estudo mais aprofundado das questões que expusemos, quais sejam, as dimensões problemáticas da relação da poesia drummondiana com a técnica. Dimensões que se viram exemplificadas, a partir de uma leitura, mesmo que fragmentada, de uma "emoção social" que passa pelas considerações do poeta, advindas do corpo, donde se elabora o pensamento que conduz o homem ao processo civilizatório, dentre o qual a dimensão bélica se destaca. 0 poeta protagoniza, então, e corrobora, uma máxima heideggeriana, aquela de que a técnica não é neutra, e tampouco é apenas uma dimensão do técnico, do qual se faria bom ou mau uso. Dessa forma, o poeta insere o homem, desde dentro, desde o início de sua jornada escritural, como um dispositivo propulsor da tragédia social em que se vê encalacrado, sem, contudo, perder a dimensão corporal, espaço único e problemático de uma transcendência mundana em cuja batalha, por fim, o homem, em "amor problemático, se dissolve na cidade, que é ele mesmo. 


\section{Referências bibliográficas}

AGAMBEN, Giorgio. 0 que é o contemporâneo? e outros ensaios. Tradução de Vinícius Nicastro Honesco. Chapecó, SC: Argos, 2012.

ANDRADE, Carlos Drummond de. Poesia 1930-62 - de Alguma poesia a Lição de coisas. Edição crítica organizada por Júlio Castañon Guimarães. São Paulo: Cosac Naify, 2012.

ANDRADE, Carlos Drummond de. Poesia completa. Rio de Janeiro: Nova Aguilar, 2002.

ANDRADE, Carlos Drummond de. 0 mundo de após-guerra. Entrevista a Ary de Andrade. In: BRYNER, Sônia (organização). Carlos Drummond de Andrade. Rio de Janeiro: Civilização Brasileira, 1977 (Coleção Fortuna Crítica, 1). p. 30-36.

BADIOU, Alain. O século. Tradução de Carlos Felício da Silveira. São Paulo: Ideias \& Letras, 2007.

BANDEIRA, Manuel. Itinerário de Pasárgada. Rio de Janeiro: Nova Fronteira, 1984.

BOSI, Alfredo. Dialética da colonização. Rio de Janeiro: Companhia das Letras, 1992.

BENJAMIN, Walter. Magia, técnica, arte e política. São Paulo: Brasiliense, 1985.

GALIMBERTI, Umberto. Psiche \& techne: o homem na idade da técnica. Tradução de José Maria de Almeida. São Paulo: Paulus, 2006. 
GLEDSON, John. Poesia e poética de Carlos Drummond de Andrade. São Paulo: Duas Cidades, 1981.

HOUAISS, Antônio. Dicionário da língua portuguesa. Rio de Janeiro: Objetiva, 2001.

REVISTA USP, São Paulo, n.69, p. 181-192, mar./maio 2006.

SIBILIA, Paula. 0 homem pós-orgânico: corpo, subjetividade e tecnologias digitais. Rio de Janeiro: Relume Dumará, 2002.

STANGOS, Nikos (organização). Conceitos de arte moderna. Tradução de Álvaro Cabral). Rio de Janeiro: Jorge Zahar Editor, 2000.

VIRILIO, Paul. Velocidade de libertação. Lisboa: Relógio D'água, 2000.

WISNIK, José Miguel (seleção e organização). Poemas escolhidos / Gregório de Matos. São Paulo: Companhia das Letras, 2010. 